\title{
PENERAPAN GMP DAN SSOP PADA PENGALENGAN IKAN LEMURU (Sardinella longiceps)
} DALAM MINYAK NABATI

\section{THE GMP AND SSOP LEMURU FISH (Sardinella longiceps) CANNING IN VEGETABLE OIL}

\author{
Al Acthur IW Lapene ${ }^{1}$, Yuliati H Sipahutar ${ }^{1 *}$, Ahadin FF Ma'roef ${ }^{1}$ \\ ${ }^{1}$ Program Studi Pengolahan Hasil Perikanan, Sekolah Tinggi Perikanan \\ JI. AUP Pasar Minggu, Jakarta Selatan, Jakarta, Indonesia \\ Korenspondensi : yuliati.sipahutar@gmail.com (YH Sipahutar) \\ Diterima 13 Agustus 2021 - Disetujui 16 September 2021
}

\begin{abstract}
ABSTRAK. GMP adalah pedoman persyaratan dan tata cara berproduksi yang baik bagi suatu unit pengolahan ikan, memastikan mutu produk dan menjamin tingkat dasar pengendalian keamanan pangan. SSOP merupakan pedoman persyaratan operasi sanitasi di unit pengolahan ikan, untuk menjamin bahwa prosedur dan proses sanitasi dilakukan secara efisien mengendalikan bahaya keamanan pangan yang umum dijumpai dilingkungan pengolahan dan operasi. Penelitian bertujuan untuk mengetahui penerapan Good Manufacturing Practices dan Sanitation Standard Operating Prosedure pada tahapan produksi pengalengan ikan Lemuru (Sardinella longiceps) dalam minyak nabati. Penelitian ini menggunakan metode survey, wawancara, observasi, dokumentasi, serta partisipasi langsung dalam kegiatan proses pengalengan ikan Lemuru. Penerapan GMP pada tahapan produksi meliputi: Penerimaan bahan baku; pengguntingan (potong kepala dan ekor); pencucian bahan baku ikan lemuru; pelepasan karton, thawing (pelelehan), penyiangan, pencucian, pencucian kaleng kosong, pengisian dalam kaleng, preccooking (pemasakan pendahuluan), penirisan, pengisian media, penutupan kaleng, pencucian kaleng, sterilisasi, pendinginan, pengkodean, inkubasi, pengepakan, penyimpanan, pengiriman. Penerapan SSOP meliputi : keamanan air dan es, peralatan dan pakaian kerja dan pencegahan kontaminasi silang, toilet dan tempat cuci tangan,bahan kimia dan saniter, syarat label dan penyimpanan, kesehatan karyawan dan pengendalian pest. Penerapan GMP dan SSOP telah dilaksanakan dengan baik untuk mengurangi kontaminasi produk akhir dan telah sesuai dengan standard prosedur yang telah ditetapkan oleh perusahaan.
\end{abstract}

KATA KUNCI: GMP, SSOP, pengalengan, ikan Lemuru

ABSTRACT. GMP is a guideline for requirements and good production procedures for a fish processing unit, ensuring product quality and ensuring a basic level of food safety control. SSOP is a guideline for sanitation operation requirements in fish processing units, to ensure that sanitation procedures and processes are carried out efficiently to control food safety hazards that are commonly encountered in processing and operating environments. This study aims to determine the application of Good Manufacturing Practices and Sanitation Standard Operating Procedures at the production stage of canning Lemuru fish (Sardinella longiceps) in vegetable oil. This study uses survey methods, interviews, observations, documentation, and direct participation in the Lemuru fish canning process. The application of GMP at the production stage includes: Acceptance of raw materials; shearing (cut off the head and tail); Washing of lemuru fish raw materials; Carton Removal, thawing (melting), Weeding, Washing, empty can washing, filling in cans, Preccooking (precooking), Draining, Media filling, Can closure, Can washing, Sterilization, Cooling, Coding, Incubation, Packaging, Storage, Shipping. The implementation of SSOP includes: water and ice safety, equipment and work clothes and prevention of cross contamination, toilets and hand washing facilities, chemicals and sanitary ware, labeling and storage requirements, employee health and pest control. The implementation of GMP and SSOP has been carried out properly to reduce contamination of the final product and is in accordance with the standard procedures set by the company.

KEYWORDS: GMP, SSOP, canning, lemuru fish

\section{Pendahuluan}

Keamanan pangan merupakan suatu hal yang penting apabila dilihat dari segi ilmu sanitasi. Apabila dikaitkan dengan adanya bahaya asal pangan (food-borne hazard) maka keamanan pangan dilakukan 
setiap tahapan rantai pangan sehingga pengendalian proses dilakukan di seluruh rantai pangan menjadi sangat penting. Keamanan pangan menjamin melalui berbagai upaya secara terpadu oleh seluruh pihak dalam rantai pangan (BRC Global Standards, 2018).

Pengolahan hasil perikanan merupakan salah satu kegiatan untuk meningkatkan nilai tambah, memperpanjang masa simpan, serta memperluas jangkauan pemasaran. Prinsip pengolahan ikan pada dasarnya bertujuan melindungi ikan dari pembusukan dan kerusakan, selain itu untuk memperpanjang daya awet dan mendiversifkasikan produk olahan hasil perikanan (Sutriyati et al., 2004). Pengalengan ikan adalah salah satu jenis pengolahan yang digunakan untuk menghambat kegiatan zat-zat mikroorganisme (Syah, 2012)

Industri pengalengan ikan di Indonesia tumbuh signifikan. Industri ini diklaim mendapat keberkahan di tengah pandemi Covid-19. Sebab, permintaan terhadap produk ini meningkat drastis . Stok nasional untuk produk sarden dan makarel kaleng saat ini berjumlah 35 juta kaleng. Selain diserap melalui pasar ekspor, ritel dan online, olahan ikan kaleng dapat dimanfaatkan sebagai salah satu produk bantuan sosial yang memenuhi kebutuhan protein masyarakat. Usaha pengolahan ikan terdapat 718 unit tersebar di berbagai wilayah Indonesia. Jumlah produksi sektor pengolahan ikan ini mencapai 1,6 juta ton pada tahun 2019, meningkat 300 ribu ton dibanding tahun 2016. "Untuk nilai ekspornya, sector industri ini juga meningkat pada tahun 2019 menjadi USD 4,1 juta (Kementerian Perindustrian, 2020). Standar mutu mutlak diterapkan untuk menjamin mutu dan keamanan pangan yang sesuai dengan tuntutan konsumen. Hal ini sejalan dengan adanya tuntutan ekivalensi sistem pembinaan dan pengawasan mutu hasil perikanan yang diterapkan di Indonesia yang ditujukan untuk melindungi konsumen.

Good Manufacturing Practices (GMP) yaitu cara berproduksi yang baik dan benar dengan implementasi untuk menghasilkan produk pangan yang berkualitas, menghasilkan produk yang benar, memenuhi persyaratan mutu (wholesomeness) dan keamanan pangan (food safety) (Pusat Sertifikasi Mutu dan Keamanan Hasil Perikanan, 2014). Faktor penting yang harus diperhatikan dalam penerapan GMP memiliki beberapa persyaratan yaitu persyaratan bahan baku dan persyaratan produk akhir harus sesuai dengan persyaratan keamanan dan mutu yang berlaku (KKP, 2019).

Sanitation Standard Operating Procedure (SSOP) adalah prosedur pelaksanaan sanitasi yang harus dipenuhi oleh suatu unit pengolahan ikan untuk mencegah terjadinya kontaminasi terhadap produk yang diolah (Winarno, 2011). Penerapan SSOP dibagi menjadi 8 (delapan) kunci persyaratan sanitasi, yaitu: 1) Keamanan air dan es ; 2) Kondisi dan kebersihan permukaan yang kontak dengan makanan; 3) Pencegahan kontaminasi silang; 4) Menjaga fasilitas pencuci tangan, sanitasi dan toilet; 5) Proteksi dari bahan-bahan berbahaya; 6) Pelabelan dan penyimpanan dan penggunaan bahan baku toksin yang benar; 7) Pengawasan kondisi kesehatan personil dan 8) Pengendalian Pest (Winarno \& Surono, 2004). Penelitian ini bertujuan untuk mengetahui penerapan GMP dan SSOP pada tahapan proses pengalengan ikan Lemuru dalam minyak nabati.

\section{Bahan dan Metode}

\subsection{Waktu dan Tempat Penelitian}

Penelitian ini dilaksanakan pada bulan Maret sampai dengan Mei 2019 di CV. Pasific Harvest, Muncar Banyuwangi.

\subsection{Alat dan Bahan Penelitian}

Alat yang digunakan adalah timbangan, meja proses, nampan sortir, tangki perebus, tangki pendingin, pisau, alat penutup kaleng, alat pelabelan dan pinset, pengukuran suhu bahan baku, produk akhir, air maupun ruangan menggunakan termometer digital. Bahan baku yang digunakan ikan lemuru (Sardinella longiceps) dalam bentuk beku. Bahan tambahan yang digunakan adalah minyak nabati. Bahan pembantu menggunakan air dan es.

\subsection{Metode Kerja}

Metode penelitian dilakukan dengan survey yang dikumpulkan melalui wawancara, observasi, dokumentasi, serta partisipasi langsung dalam kegiatan proses pengalengan ikan Lemuru (Sardinella 
longiceps) dalam minyak nabati. Analisa data dilakukan dengan metode deskriptif. Pengujian organoleptik menggunakan score sheet ikan beku SNI 4110:2014 (Badan Standardisasi Nasional, 2014) dan keamanan pangan sarden dan makerel dalam kemasan kaleng SNI 8222:2016 (Badan Standardisasi Nasional, 2016).

\section{Hasil dan Pembahasan}

\subsection{Alur Proses Pengalengan Lemuru dalam Minyak Nabati}

Proses pengalengan lemuru dalam minyak nabati adalah sebagai berikut:

a) Penerimaan Bahan Baku

Bahan baku ikan lemuru diterima dalam keadaan beku yang dikemas dalam plastik dan master karton menggunakan kendaraan container berkapasitas mencapai 27 ton, dengan suhu $-17,16^{\circ} \mathrm{C}$ sesuai standar mutu ikan beku pada SNI 4110-2014. Petugas QC melakukan pengecekan, pencatatan dan pengujian terhadap kualitas ikan dengan mencatat perusahaan pemasok, nomor polisi kendaraan, nomor container, jenis ikan, asal ikan, berat ikan (ton), ukuran ikan dalam satu kilogram dan suhu container Hal ini untuk mengetahui semua pihak yang terlibat dalam mata rantai produksi (Masengi et al., 2016). Sesuai dengan Suryanto \& Sipahutar, (2020) proses penanganan bahan baku dari pasca panen hingga masuk ke perusahaan dilakukan dengan cepat, dingin, cermat dan bersih.

b) Pelepasan Karton

Pelepasan karton yang dilakukan dengan peralatan yang saniter dan terjamin kebersihannya. Peralatan yang digunakan untuk membuka karton seperti gunting atau pisau. Proses pelepasan karton dan polybag dilakukan dengan hati-hati agar tidak merusak produk di dalamnya.

c) Thawing (Pelelehan)

Proses thawing dilakukan dengan memasukkan setiap blok ikan beku ke dalam bak thawing, menggunakan air karena waktunya lebih cepat. Satu bak thawing terisi oleh 100 blok ikan beku berukuran sekitar 10 kilogram per blok ikan. Blok ikan beku yang sudah berada di dalam bak thawing dialiri oleh air dengan cara membuka kran saluran air dan dibiarkan mengalir.. Waktu pelelehan sangat tergantung dari ukuran dan volume ikan dalam satu bak (Irianto \& Akbarsyah, 2007). Proses thawing dilakukan pada sore hari setelah produksi selesai dan didiamkan selama 12 jam. Keesokan harinya karyawan yang bertugas akan merendam ikan dengan menggunakan air selama 30 menit. Suhu ikan setelah proses thawing yang diharapkan maksimal $4^{\circ} \mathrm{C}$, sesuai standar dengan suhu yang tepat maka kesegaran ikan dapat terjaga (Zhafirah \& Sipahutar, 2021).

d) Penyiangan

Proses penyiangan ikan dilakukan dengan gunting khusus yang tajam berbahan stainless, di atas meja khusus penyiangan dan didesain untuk mudah dibersihkan. Proses penyiangan dilakukan cepat, cermat dan saniter dengan cara memotong kepala ikan mulai dari bagian punggung ikan sekaligus menarik isi perut ikan sampai bersih serta memotong ekor ikan. Es balok yang sudah dihancurkan ditambahkan pada proses penyiangan untuk mempertahankan mutu ikan.

\section{e) Pencucian}

Proses pencucian ikan dilakukan secara otomatis dengan menggunakan mesin pencucian ikan, yaitu rotary drum yang berbentuk silinder, berdiameter satu meter dan panjang dua meter yang setengah bagiannya terendam dalam air yang mengalir, memiliki bentuk yang berlubang-lubang dan bergerak dengan cara berputar. Di dalam mesin terdapat plat spiral yang berfungsi untuk membawa ikan keluar secara otomatis setelah proses pencucian. 


\section{f) Pencucian Kaleng Kosong}

Pencucian kaleng kosong dilakukan secara otomatis menggunakan mesin pencuci kaleng, dengan cara meletakkan kaleng pada konveyor menuju mesin pencuci kaleng, dan menyemprotkan air serta uap panas dari dalam mesin pencuci kaleng. Kaleng dicuci dengan menggunakan larutan chlorin 100 ppm. Pencucian kaleng dilakukan untuk membersihkan kaleng dari debu yang menempel pada kaleng bagian dalam maupun luar yang dapat mengkontaminasi produk (Ma'roef et al., 2021). Hasil dari pencucian kaleng selanjutnya dibawa ke tempat canning untuk melakukan pengisian ikan lemuru.

g) Pengisian dalam Kaleng

Ikan dimasukkan ke dalam kaleng secara manual oleh karyawan yang dilakukan secara cepat, cermat dan saniter sesuai dengan berat yang sudah ditetapkan. Pengisian ikan harus dimasukan berseling antara tubuh bagian atas dan tubuh bagian bawah agar berat dan jumlah ikan sesuai dengan spesifikasi produk (Sipahutar et al., 2010). Ikan - ikan lemuru yang besar atau sedang umumnya dikemas dalam kaleng berdiameter 3,01 inchi, dan yang berukuran kecil dikemas dalam kaleng yang berdiameter 2,02 inch (Vatria, 2006). Selain itu, dalam pengisian ikan harus memperhatikan head space pada kaleng. Menurut Adawyah, (2014), head space adalah ruangan kosong yang tersisa antara tutup dengan produk. Fungsi dari head space yaitu sebagai ruang cadangan untuk pengembangan produk selama proses pemanasan (sterilisasi) agar produk tidak menekan wadah karena dapat menyebabkan kaleng menjadi kembung. Kaleng yang telah diisi selanjutnya akan dilakukan proses seamer yaitu penggabungkan antara badan kaleng dengan tutup kaleng (Fatkhurrozi Syah \& Pramono, 2019) Pengisian dilakukan dengan memasukkan ikan ke dalam kaleng dengan berat standar sebagai berikut:

Tabel 1. Standar Jumlah Ikan Dalam Satu Kaleng.

\begin{tabular}{ccc}
\hline Jenis kaleng/ Berat kaleng & Jumlah ikan & Size ikan per $(\mathbf{k g})$ \\
\hline CLUB CAN $(206 \times 402 \times 103) \pm 125 \mathrm{gr}$ & $3-5$ ekor & $20-25$ \\
\hline
\end{tabular}

\section{h) Precooking (Pemasakan Pendahuluan)}

Precooking atau pemasakan pendahuluan dilakukan dengan menggunakan alat exhaust box dengan suhu $90-100^{\circ} \mathrm{C}$ selama 15 menit (Irianto \& Giyatmi, 2015). Proses pemasakan pendahuluan dilakukan secara otomatis menggunakan konveyor berjalan yang berada di dalam exhaust box. Kalengkaleng berisi ikan dimasukkan ke dalam alat exhaust box oleh petugas secara manual. Exhaust box bekerja menggunakan uap panas yang dihasilkan dari mesin boiler yang terhubung melalui pipa-pipa besi. Pada alat exhaust box terdapat manometer untuk menunjukkan suhu exhaust box.

i) Penirisan

Proses penirisan dilakukan secara otomatis dengan menggunakan alat penirisan yang terhubung oleh konveyor berjalan. Kaleng yang baru keluar dari alat exhaust box diatur oleh karyawan penirisan supaya kaleng-kaleng dapat masuk secara teratur di konveyor yang telah terhubung ke alat penirisan. Kaleng-kaleng akan berjalan pada konveyor dengan posisi kaleng horizontal dengan kemiringan $45^{\circ}$.

j) Pengisian Media

Ikan yang berada di dalam kaleng kemudian akan diisi dengan media vegetable oil. Pengisian media vegetable oil dilakukan dengan kaleng-kaleng ikan berada di atas konveyor berjalan kemudian kaleng ikan tersebut akan terisi media melalui pipa saluran pengisian media yang berada di atasnya. Pengisisan media dilakukan secara otomatis diatas konveyor berjalan yang terhubung oleh alat penirisan dan alat penutupan kaleng (Masengi \& Sipahutar, 2016).

k) Penutupan Kaleng

Kaleng yang berisi ikan dan sudah ditambahkan media vegetable oil kemudian diletakkan diatas ban berjalan di atas konveyor menuju alat penutupan kaleng (seamer). Mesin seamer memiliki four head seamer yang mana dalam satu putaran hanya dapat menutup empat kaleng dengan kecepatan penutupan kaleng sebanyak 150 kaleng setiap menitnya. Setiap mesin seamer memiliki kode yang berbeda-beda (Kusnandar, 2010). Prinsip kerja mesin seamer disebut juga "Double seam". Double seam adalah proses penyambungan tutup dan body kaleng dengan dua operasi roll (first roll dan second roll) 
(Arini \& Sri Subekti, 2019). Petugas QC seamer bertugas untuk menguji kaleng setelah kaleng ditutup dengan mesin seamer. Pengambilan sebanyak 10 sampel kaleng dilakukan secara berkala setiap dua jam sekali.(Maurina \& Sipahutar, 2021). Parameter pengujian yang dilakukan diantaranya adalah Countershink Depth, Seam Width, Seam Thickness, Body Hook, Cover Hook, Overlap Double Seam, Wrinkle dan Tightness. Standar parameter pengujian secara teardown. Pengujian hasil penutupan kaleng dilakukan menggunakan alat seam micrometer, countershink dengan bantuan alat tang untuk membuka tutup kaleng. Jika hasil lipatan kaleng tidak sesuai dengan standar, maka proses penutupan kaleng dihentikan sementara untuk dilakukan pengecekan mesin seamer oleh teknisi mesin (Irianto \& Giyatmi, 2015).

Tabel 2 . Standar Hasil Pengujian Kaleng Secara Teardown.

\begin{tabular}{clcc}
\hline No & \multicolumn{1}{c}{ Pengujian } & Parameter & Standar Perusahaan (mm) \\
\hline 1 & Countershink Depth $(\mathrm{C})$ & & $3,45-3,85$ \\
2 & Seam Width $(\mathrm{W})$ & Lebar Lipatan & $2,60-3,00$ \\
3 & Seam Thickness $(\mathrm{T})$ & Tebal Lipatan & $1,13-1,23$ \\
4 & Body Hook $(\mathrm{BH})$ & Kaitan badan & $1,65-2,05$ \\
5 & Cover Hook $(\mathrm{CH})$ & Kaitan Tutup & $1,65-2,05$ \\
6 & Overlap Double Seam $(\mathrm{OL})$ & & Min 1,00 \\
7 & Wrinkle $(\%)$ & Kerutan pada Lipatan & Max $30 \%$ \\
8 & Tightness $(\%)$ & Tingkat Kerapatan & Min $70 \%$ \\
\hline
\end{tabular}

Sumber: CV. Pasific Harvest, 2019.

I) Pencucian kaleng

Kaleng yang sudah ditutup menggunakan mesin seamer kemudian dimasukkan ke dalam mesin pencuci kaleng melalui konveyor berjalan yang saling terhubung dengan mesin seamer. Kaleng yang sudah ditutup masih dalam keadaan belum bersih karena masih adanya sisa media vegetable oil yang menempel di permukaan luar kaleng. Di dalam mesin pencuci kaleng, kaleng akan disemprotkan dengan air, uap panas dan sabun khusus pencuci kaleng yang berstandar food grade. Air tersebut disemprotkan melalui pipa-pipa yang berlubang yang dapat menyemprotkan air ke tiga titik yang berbeda (Sofiah \& Ramli, 2012).

m) Sterilisasi

Keranjang yang telah terisi penuh oleh produk kaleng selanjutnya diangkat menggunakan katrol otomatis untuk kemudian dimasukkan ke dalam mesin retort. Setelah retort ditutup dengan rapat dan membuka kran venting. Tahap pertama adalah proses venting dan tahap kedua adalah proses sterilisasi. Pada proses venting, tekanan yang digunakan adalah 0,38 atm dengan suhu $109-110^{\circ} \mathrm{C}$ selama 10 menit (Sahubawa \& Ustadi, 2019). Venting bertujuan untuk menghilangkan sisa air, udara dan uap yang masih tersisa di dalam retort. Kemudian kran venting ditutup ketika sudah 10 menit dan dilakukan proses sterilisasi dengan mengatur tekanan menjadi 0,87 atm. Setelah tekanan menunjukkan 0,87 atm selanjutnya nyalakan tombol timer pada mesin Automatic Sterilization Controller (ASC). Waktu yang dibutuhkan untuk proses sterilisasi berbeda-beda untuk setiap ukuran kaleng. Untuk kaleng ukuran club can $(206$ x 402 x 103) \pm 125 gr menggunakan waktu sterilisasi selama 90 menit. Standar suhu CV. Pasific untuk kaleng club can $(206 \times 402 \times 103) \pm 125 \mathrm{gr}$ adalah $118^{\circ} \mathrm{C}$ dan waktunya 90 menit. Pengawasan proses sterilisasi dilakukan oleh petugas $Q C$ dengan melakukan pencatatan yang terdiri dari kode retort, merk produk, ukuran kaleng, waktu sterilisasi, suhu dan tekanan retort, waktu pertama melakukan sterilisasi dan waktu selesai sterilisasi. Pencatatan suhu dan tekanan retort dilakukan selama proses sterilisasi berlangsung setiap lima menit sekali. Setelah waktu yang diperlukan sudah terpenuhi selanjutnya dilakukan proses pendinginan.

n) Pendinginan

Saat waktu sterilisasi sudah terpenuhi, alarm pada alat ASC akan menyala kemudian matikan control uap di ASC tekan panel control cooling dan kran venting atas di tutup, kemudian dilakukan proses pendinginan. Proses ini dilakukan di dalam retort dengan cara menaikkan tekanan yang semula menjadi 
1 atm kemudian mengalirkan air ke dalam retort melalui saluran air yang terdapat di bagian bawah retort. Saat air sudah masuk ke dalam retort, tekanan diturunkan secara perlahan dengan membuka sedikit demi sedikit kran venting menjadi 0,8 atm sampai keluar air di kran blider samping. Tekanan diturunkan dan dipertahankan pada batas $0,6 \mathrm{~atm}$, kemudian membuka dan menutup kran venting untuk memancing air keluar dari dalam retort melalui kran breeder samping., kran venting dibuka sepenuhnya supaya tekanan dalam retort turun. Proses pendinginan berlangsung selama \pm 20 menit. Produk dianggap telah melewati proses pendinginan jika telah mencapai suhu $40^{\circ} \mathrm{C}$.

o) Pengkodean

Kaleng di dalam keranjang diangkat secara manual oleh karyawan ke atas meja pengkodean. Kaleng di atas meja dibersihkan terlebih dahulu secara manual oleh karyawan dengan cara kaleng digosok menggunakan kain bersih untuk membersihkan kotoran dan becak air yang ada di permukaan luar kaleng, kemudian kaleng yang sudah bersih digeser ke meja pengkodean menggunakan konveyor berjalan. Kaleng diposisikan terbalik dengan posisi pembuka kaleng berada di bawah. Kaleng yang berjalan di atas konveyor akan dilakukan pengkodean secara otomatis menggunakan alat ink jet printer yang bekerja menggunakan sensor otomatis. Setiap saat pengkodean, dilakukan pengecekan oleh petugas QC untuk menyeleksi kaleng-kaleng yang rusak secara fisik. Jika ditemukan kaleng rusak maka kaleng tersebut akan dipisahkan. Hasil printing juga dicek oleh petugas QC pada setiap kaleng. Pengkodean terdiri dari kode produksi, waktu produksi dan waktu kadaluarsa produk yang bertujuan sebagai informasi produk (Badan Pengawas Obat dan Makanan Republik Indonesia, 2019). Produk yang telah diberi kode selanjutnya akan berjalan di atas konveyor ke sebuah meja kemudian dimasukkan ke dalam kemasan karton secara manual oleh karyawan untuk dilakukan proses inkubasi.

p) Inkubasi

Proses inkubasi bertujuan untuk mengidentifikasi adanya critical defects (bocor dan kembung) pada kaleng yang disebabkan oleh bakteri Clostridium botulinum (Supenah, 2019). Proses ini juga untuk mengetahui kesempurnaan proses sterilisasi. Proses inkubasi dilakukan selama 5-7 hari dalam suhu ruang. Setiap pallet akan diberi label inkubasi oleh petugas $Q C$ menggunakan kertas berwarna biru yang ditempelkan pada salah satu karton di setiap pallet. Dalam label inkubasi tertera informasi berupa nama produk, kode produksi, tanggal produksi, nomor pallet, jumlah produk, tanggal selesai inkubasi dan kolom paraf petugas QC. Prosedur penginkubasian produk kaleng sudah sesuai dengan SNI 8222:2016 yang menyatakan kaleng disimpan selama 5-12 hari pada suhu ruang (Badan Standardisasi Nasional, 2016).

q) Pengepakan

Produk yang telah dinyatakan release selanjutnya dilakukan tahap pengepakan. Sebelum pengepakan dilakukan penyortiran produk terlebih dahulu. Produk yang rusak setelah proses inkubasi akan dipisahkan dan dibawa ke area bad stock dan untuk produk yang lolos penyortiran, selanjutnya akan dilakukan proses pengepakan. Dalam satu pallet berisikan 60 karton berisi produk yang selanjutnya akan dibawa ke dalam ruang penyimpanan produk. Setiap pallet akan diberi label realse oleh petugas QC menggunakan kertas berwarna kuning yang ditempelkan pada salah satu karton disetiap pallet. Dalam label realese tertera informasi berupa nama produk, kode produksi, tanggal produksi, nomor pallet, jumlah produk, dan kolom paraf $Q C$.

r) Penyimpanan

Produk yang telah dikemas menggunakan karton kemudian disusun di atas sebuah pallet dengan susunan satu pallet berisikan 60 master carton. Pallet tersebut kemudian dibawa ke gudang penyimpanan menggunakan hand pallet manual. Penyimpanan dilakukan dengan menyusun master karton di atas pallet di ruang penyimpanan menggunakan suhu pengengkutan produk ketika akan dibawa dan dimasukkan ke dalam truk pengangkut ruang. Penyusunan barang dalam gudang dilakukan dengan memperhatikan jarak antar pallet. Penyusunan pallet tidak diperbolehkan bersentuhan dengan dinding dengan tujuan untuk menghindari kelembaban yang akan menyebabkan kerusakan pada kemasan (Zahirah, 2020). Hal ini dilakukan dengan menerapkan sistem first in first out (FIFO) pada tahap penyimpanan dimana produk yang masuk terlebih dahulu ke dalam gudang akan didistribusikan pertama kali (Hadinata \& Adriyanto, 2020). 


\section{s) Pengiriman}

Produk yang sudah disimpan di gudang kemudian dibawa kedalam truk kontainer untuk didistribusikan kepada buyer di tiap-tiap daerah. Proses pengiriman dilakukan dengan menggunakan kontainer, bertujuan untuk melindungi produk dari kontaminasi selama proses pengiriman. Pemuatan produk kedalam kontainer menggunakan forklift dan penyusunannya dilakukan oleh karyawan.

\subsection{Pengamatan Suhu Proses Pengalengan}

Pengamatan suhu proses pengalengan di CV. Pasific Harvest dilakukan di beberapa tahapan proses, diantaranya adalah penerimaan bahan baku, ruang cold storage, thawing, media air, penyiangan, pencucian, air pencucian, pengisian ikan ke dalam kaleng, precooking, alat exhaust box, media vegetable oil, air pencucian kaleng, sterilisasi, suhu ruang inkubasi dan suhu ruang penyimpanan. Berikut adalah rata-rata hasil pengamatan suhu proses pengalengan:

Tabel 3. Hasil Pengamatan Suhu Pada Beberapa Tahapan Proses.

\begin{tabular}{clcc}
\hline No & \multicolumn{1}{c}{ Tahapan Proses } & Pengamatan & Rata-rata $\left({ }^{\circ} \mathrm{C}\right)$ \\
\hline 1 & Penerimaan BB & Ruangan & $-17,16$ \\
2 & Cold storage & Ruangan & $-19,20$ \\
3 & Thawing & Ikan & 0,56 \\
4 & Air Thawing & Media & 22,79 \\
5 & Penyiangan & Ikan & 4,64 \\
6 & Pencucian & Ikan & 4,86 \\
7 & Air pencucian Ikan & Media & 4,59 \\
8 & Pengisian & Ikan & 6,67 \\
9 & Precooking & Ikan & 85,96 \\
10 & Exhaust box & Media & 90 \\
11 & Media vegetable oil & Media & 82,19 \\
12 & Air pencucian & Media & 75,51 \\
13 & Sterilisasi & Media & 118 \\
14 & Inkubasi & Ruangan & 28,59 \\
15 & Penyimpanan & Ruangan & 29,30 \\
\hline
\end{tabular}

Sumber: CV. Pasific Harvest, 2019.

Pada proses penerimaan bahan baku suhu ikan selalu terjaga melalui proses penurunan ikan dari container menuju cold storage yang dilakukan dengan cepat. Dari tabel diatas dapat dilihat pada proses preparasi bahan baku suhu rata-ratanya adalah $-17,16^{\circ} \mathrm{C}$. Kenaikan suhu bahan baku dikarenakan tempat proses pengolahan lemuru terpisah dengan cold storage, yang berjarak sekitar $\pm 100 \mathrm{~m}$. Hal ini tidak mempengaruhi mutu bahan baku karena proses pengantaran bahan baku menggunakan truk khusus dan bahan baku dilapisi oleh kemasan sekunder berupa master karton dan polybag untuk menjaga kualitas bahan baku.Pada proses thawing dilakukan pengukuran suhu yaitu suhu media (air), yaitu rata-rata $22,79^{\circ} \mathrm{C}$, hal ini dikarenakan air yang digunakan untuk proses thawing adalah air biasa (tidak dingin). Setelah proses thawing selesai, maka panelis melakukan pengukuran suhu ikan dengan rata-rata suhu ikan yaitu $0,56^{\circ} \mathrm{C}$. Setelah proses thawing selesai, ikan langsung dimasukan kedalam keranjang untuk dibawa ke meja penyiangan.

Panelis menuju ke meja penyiangan untuk melakukan pengukuran suhu saat sebelum disiangi, panelis kembali melakukan pengukuran suhu ikan dan suhu yang terbaca oleh thermometer. Setelah ikan dibersihkan dan dipotong sesuai dengan spesifikasi, panelis kembali melakukan pengecekan suhu. Suhu rata-rata ikan setelah disiangi dan dipotong adalah 4,64ㅇ. Kesegaran ikan dijaga dengan cara menyiramkan daging ikan dengan air di baskom yang telah dicampurkan dengan es (Astawan, 2019). Setelah melakukan 12 kali pengamatan dan 2 kali pengulangan maka didapat rata-rata suhu pada proses ini yaitu $6,67^{\circ} \mathrm{C}$. 
Pengukuran suhu dilanjutkan pada proses pemasakan pendahuluan (pre-cooking). Setelah itu ikan dimasak di dalam exhaust box dengan menggunakan suhu rata-rata $90^{\circ} \mathrm{C}$ selama 15 menit. Setelah melalui proses pre-cooking, panelis kembali mengukur suhu daging ikan yaitu rata-rata $85,96{ }^{\circ} \mathrm{C}$. Pengamatan suhu pada proses pengisian medium dilakukan dengan melihat manometer yang terdapat pada tanki penampungan di atas pipa pengisian. Hasil rata-rata suhu medium adalah $82,19^{\circ} \mathrm{C}$. Hal ini diperolah karena media dilakukan pemasakan sebelumnya pada suhu $90-95^{\circ} \mathrm{C}$. Hal ini sudah sesuai dengan standar Perusahaan CV. Pasific Harvest dimana suhu medium minimal $70^{\circ} \mathrm{C}$.

Hasil pengamatan pencucian kaleng didapatkan rata-rata $75,51^{\circ} \mathrm{C}$ karena air pencucian yang digunakan ditambahkan dengan uap panas yang dihasilkan dari boiler. Tujuan penetapan suhu minimal $70^{\circ} \mathrm{C}$ pada air pencucian kaleng adalah untuk mendapatkan hasil pencucian kaleng yang baik. Suhu minimal $70^{\circ} \mathrm{C}$ digunakan supaya mempermudah pencucian kaleng dari sisa media vegetable oil yang menempel dipermukaan kaleng. Sebelum proses sterilisasi, kaleng terlebih dahulu dimasukan kedalam keranjang retort yang direndam didalam bak penampungan. Proses dilakukan selama 15 menit, sehingga untuk pengukuran suhu sebelum proses sterilisasi, panelis mengestimasikan suhu air bak penampungan sama dengan suhu produk. Suhu retort untuk pengalengan ikan sarden yaitu $118^{\circ} \mathrm{C}$. Pengamatan suhu penyimpanan dilakukan dengan mengamati thermometer ruangan yang terdapat di dalam ruang inkubasi dan penyimpanan. Hasil rata-rata pengamatan suhu ruang inkubasi yaitu $28,59^{\circ} \mathrm{C}$ dan penyimpanan yaitu $29,30^{\circ} \mathrm{C}$. Hal ini diperoleh karena proses inkubasi dan penyimpanan dilakukan di dalam suhu ruang.

\subsection{Pengamatan GMP (Good Manufacturing Practices)}

Good Manufacturing Practices (GMP) merupakan suatu pedoman cara memproduksi makanan dengan tujuan agar produsen memenuhi persyaratan -persyaratan yang telah ditentukan untuk menghasilkan produk makanan yang bermutu sesuai dengan tuntutan konsumen (Thaheer, 2005). Keinginan perusahaan menghasilkan produk yang aman untuk dikonsumsi menjadi motivasi dalam menjalankan proses produksi, sehingga kepuasan konsumen terpenuhi. Penerapan GMP yang baik bertujuan untuk menghasilkan produk yang bermutu, sedangkan penerapan SSOP yang baik bertujuan untuk menghasilkan produk yang sehat, aman dan bebas dari kontaminan (Winarno, 2011).

a) Seleksi Bahan Baku

Bahan baku ikan lemuru diseleksi oleh petugas QC penerimaan bahan baku secara langsung pada saat bahan baku tiba di perusahaan. Bahan baku yang diterima berupa ikan lemuru (Sardinella longiceps) dalam bentuk utuh beku. Pengangkutan bahan baku menggunakan container yang memiliki unit pendingin untuk menjaga rantai dingin pada saat pengangkutan dengan disimpan menggunakan kemasan plastik dan master karton. Bahan baku diperiksa oleh petugas QC mengenai mutu dengan pengujian organoleptik dan pengujian kimia. Batas mutu pengujian organoleptik bahan baku yang diterima harus bernilai lebih dari 7 dan batas mutu pengujian kimia untuk kadar histamin harus kurang dari 50 ppm. Pembongkaran diakukan di dekat pintu cold storage. Setiap blok ikan beku dikeluarkan satu persatu yang disusun di atas pallet kemudian dimasukkan ke dalam cold storage menggunakan forklift dan hand pallet manual dengan cepat, bersih dan hati-hati untuk mencegah kerusakan dan menjaga suhu ikan (Ma'roef et al., 2021).

b) Penanganan dan Pengolahan

Penanganan ikan dilakukan dengan sistem FIFO (First In First Out) yaitu ikan yang lebih awal datang akan diproses terlebih dahulu. Proses produksi ikan dilakukan secara cepat dan hati-hati dengan tetap menjaga rantai dingin dengan melakukan penambahan es sampai proses pengisian ikan ke dalam kaleng. Setiap tahapan proses pengalengan dilakukan pengawasan oleh petugas QC. Penanganan dan pengolahan dilakukan dengan baik mulai dari penangananan rantai dingin dan bahan baku sampai dengan produk disimpan di gudang dengan penerapan First In First Out (FIFO). Sesuai (Mayangsari \& Sipahutar, (2021) bahan baku harus mendapatkan pengawasan 
yang terus-menerus mulai saat ditangkap dan selama proses penanganan maupun pengolahan berlangsung, diupayakan agar tetap dalam keadaan dingin selama proses pengolahan dan harus berpindah secara cepat dari satu tahap ke tahap berikutnya dalam rantai pengolahan.

c) Persyaratan Bahan Pembantu dan Bahan Kimia

Es yang digunakan sebagai bahan pembantu adalah es balok yang dihancurkan terlebih dahulu menggunakan ice crusher. Es berfungsi untuk membantu mempertahankan rantai dingin untuk menjaga kualitas ikan. Air yang digunakan adalah air yang bersumber dari air tanah yang telah melalui treatment sehingga memiliki mutu sesuai dengan standar air minum. Air dan es yang digunakan telah memenuhi standar persyaratan air minum. Bahan kimia yang digunakan adalah klorin yang digunakan untuk tempat cuci kaki dan sabun yang digunakan untuk pembersihan alatalat. Untuk alat kebersihan yang disimpan pada ruangan khusus dan memiliki tanda yang jelas. Sehingga bila proses pengolahan telah selesai petugas yang bertugas untuk membersihkan dapat mengambil alat-alat kebersihan yang ada di tempat tersebut. Bahan kimia yang digunakan untuk pembersihan diletakkan berbeda dengan ruang pengolahan (Hafina et al., 2021).

\section{d) Pengemasan}

Bahan pengemas yang digunakan dalam pengalengan ikan telah memenuhi persyaratan mutu dan keamanan pangan yang meliputi dapat melindungi dan mempertahankan mutu, tidak berpengaruh terhadap isi, menjamin keutuhan dan keaslian isinya, tahan terhadap perlakuan selama pengolahan dan pengangkutan, tidak membahayakan kesehatan konsumen (Syarief \& Syukri, 2016). Bahan pengemas yang digunakan dalam proses pengalengan ikan terdiri dari kemasan primer dan kemasan sekunder. Bahan pengemas selalu di monitoring pada saat diterima. Bahan pengemas ditangani, disimpan dan disusun sedemikian rupa untuk mencegah kerusakan. Produk ikan kaleng yang sudah melewati proses inkubasi dan dinyatakan release akan dikemas menggunakan karton. Menurut Astawan (2007), bahan pengemas harus terbuat dari jenis bahan yang memenuhi syarat bagi produk, metode pengolahan dan pemasarannya. Bahan pengemas harus disimpan dengan cara yang bersih dan saniter. Pengemas tersebut harus tidak menularkan senyawa-senyawa yang menimbulkan kerusakan yang melampaui batas yang diperkenankan pada produk yang dikemas.

\section{e) Teknik Penyimpanan}

Penyimpanan bahan baku, bahan media, bahan pengemas dan produk akhir dilakukan di ruangan yang terpisah. Bahan kimia disimpan di ruangan tersendiri dan diawasi agar tidak mencemari produk. Bahan media dan bahan pengemas yang disimpan diberi identitas berupa tanggal penerimaan, asal bahan, nama supplier, jenis bahan dan jumlah bahan. Ruang penyimpanan beku (cold storage) diatur pada suhu $-18^{\circ} \mathrm{C}$ s/d $-21^{\circ} \mathrm{C}$ (Gusdi \& Sipahutar, 2021). Proses penyimpanan dilakukan dengan menumpuk produk yang sudah dikemas menggunakan karton di atas sebuah pallet, untuk mempermudah pengangkutan produk ketika akan dibawa dan dimasukkan ke dalam truk pengangkut. Pengaturan penyimpanan dilakukan berdasarkan pada prinsip FIFO (First In First Out) (Jacobus \& Sumarauw, 2018). Ruang penyimpanan pabrik harus dirancang sebaik mungkin, tidak lembab, mudah dibersihkan dan terpisah dengan ruang penyimpanan lainnya untuk mencegah terjadinya kontaminasi silang. Gudang penyimpanan bahan baku harus terpisah dari gudang penyimpanan produk jadi. Demikian pula dengan gudang penyimpanan bahan kimia dan pestisida harus diletakkan terpisah jauh dari area tempat makanan diproses dan disimpan (Thaheer, 2005).

f) Distribusi

Produk yang telah direlease kemudian dilakukan pendistribusian. Pendistribusian produk dilakukan dengan menggunakan container. Produk dari gudang penyimpanan dipindahkan ke dalam container menggunakan forklift dan disusun di dalam container oleh karyawan dengan hatihati. Pengiriman dilakukan melalui jalur darat serta jalur air. Jalur darat menggunakan truk, sedangkan jalur air menggunakan kapal. CV. Pasific Harvest menerapkan sistem first in first out 
(FIFO) pada tahap penyimpanan dimana produk yang masuk terlebih dahulu ke dalam gudang akan didistribusikan pertama kali. Distribusi dilakukan ke dalam dan luar negeri. Menurut Astawan (2007), pengangkutan harus dilakukan dengan hati-hati agar produk terhindar dari suhu tinggi selama pemuatan dan pembongkaran kendaraan pengangkut. Semua kendaraan yang digunakan untuk pengangkutan produk beku harus mampu mempertahankan suhu dingin yang dibutuhkan untuk mengawetkan produk beku.

\subsection{Indeks Keanekaragaman Jenis Lamun}

Penerapan Sanitation Standard Operating Prosedure (SSOP) di CV. Pasific Harvest telah dilaksanakan dengan baik dan cukup efektif untuk mengurangi/menghilangkan kontaminasi terhadap produk akhir dan telah sesuai dengan standard prosedur yang telah ditetapkan oleh perusahaan. Sanitasi yang dilakukan terdiri dari 8 (delapan) aspek sebagai berikut:

a) Keamanan Air dan Es

Air yang digunakan dalam proses produksi dan penggunaannya kontak langsung dengan produk sesuai dengan standar persyaratan air minum. Air yang digunakan adalah air tanah dan disimpan pada tandon air yang saniter dan hygiene. Jalur pipa air dirancang sedemikian rupa untuk menjamin adanya jalur yang terpisah antara air untuk produksi, air untuk sanitasi dan air limbah untuk produksi. Es yang digunakan adalah es balok yang berasal dari dari pabrik es yang lokasinya berada di daerah Muncar. Es balok yang diterima dilengkapi dengan sertifikat hasil analisa mutu air yang digunakan dalam pembuatan es. Es balok yang akan digunakan dihancurkan terlebih dahulu menggunakan ice crusher. Berdasarkan hasil pengujian sampel air dan es secara mikrobiologi disimpulkan bahwa kualitas air dan es tergolong baik, karena hasil pengujian $E$. coli dan coliform masih sesuai dengan batas persyaratan SNI 01-3553-2006 dan SNI 01-4872.2-2006.

Tabel 4. Hasil Pengujian Kualitas Air dan Es Secara Mikrobiologi

\begin{tabular}{cccccc} 
No & Sampel & Parameter Uji & Satuan & Syarat Mutu & Hasil \\
\hline 1 & \multirow{2}{*}{ Air } & E. coli & APM $/ \mathrm{ml}$ & 0 & 0 \\
& & Coliform & APM $/ \mathrm{ml}$ & 0 & 0 \\
2 & \multirow{2}{*}{ Es Balok } & E. coli & APM $/ \mathrm{ml}$ & 0 & 0 \\
& & Coliform & APM $/ \mathrm{ml}$ & 0 & 0 \\
\hline
\end{tabular}

Sumber: CV. Pasific Harvest, 2019.

Sebagai bahan baku dalam pembuatan es atau sebagai bahan baku pangan, air harus bebas dari coliform dan sumber pencemar lainnya. Sumber air bagi industri pangan dapat berasal dari Perusahaan Air Minum (PAM), sumur atau air laut. Untuk menjamin kebersihan air tersebut perlu dilakukan monitoring setiap 6 bulan sekali secara berkala.

b) Permukaan Peralatan yang Kontak dengan Produk

Pembersihan dan sanitasi dilakukan setiap hari saat sebelum dan sesudah produksi. Perlengkapan kerja seperti sarung tangan, apron dan seragam lain yang digunakan dalam proses produksi disediakan oleh perusahaan dan perlakuan sanitasinya seperti laundry dilakukan secara internal. Semua peralatan yang digunakan dilakukan pengecekan secara berkala dan dilakukan penggantian untuk yang perlu diganti. Ruang produksi dilengkapi dengan ruangan yang digunakan untuk melakukan sanitasi peralatan dan tempatnya terpisah dengan area produksi. Peralatan dan perlengkapan produksi yang sudah dibersihkan disimpan dengan rapi dan dipisah sesuai dengan jenis dan fungsinya.

c) Pencegahan Kontaminasi Silang

Karyawan memasuki ruang produksi harus menggunakan seragam dan perlengkapan kerja dengan baik dan benar sesuai dengan aturan yang telah ditetapkan. Karyawan mencuci tangan sebelum dan sesudah memasuki ruang produksi, melewati kolam footbath yang telah ditambahkan larutan desinfektan, tidak berkuku panjang, tidak memakai aksesoris yang berpeluang 
menimbulkan kontaminasi silang pada produk serta harus mencuci tangan dengan baik dan benar setelah kembali dari toilet (Thaheer, 2005). Di dalam ruang produksi, karyawan harus menggunakan peralatan kerja yang sesuai dengan standar yang telah ditetapkan, tidak boleh mengobrol kecuali bertanya kepada pengawas untuk kepentingan produksi, tidak boleh meludah dan bersin di sembarang tempat serta tidak boleh makan dan minum di area produksi. Permukaan peralatan kerja, bahan pengemas dan produk akhir tidak boleh bersentuhan langsung dengan lantai (Putrisila \& Sipahutar, 2021). Fasilitas bangunan internal unit produksi terbuat dari bahan yang tidak menimbulkan terjadinya peluang kontaminasi silang seperti tahan terhadap air, tidak mudah pecah dan mudah dibersihkan. Semua lampu di area produksi diberi cover untuk menghindari terjadinya kontaminasi pada produk apabila terjadi insiden lampu pecah.

d) Fasilitas Cuci Tangan, Sanitasi dan Toilet

Fasilitas sanitasi karyawan seperti wastafel, footbath dan toilet di disediakan secara memadai sesuai dengan jumlah karyawan yang bekerja di area produksi. Wastafel dan foothbath ditempatkan di setiap akses keluar masuk ruang produksi dan akses keluar masuk toilet. Toilet disediakan terpisah untuk pria dan wanita. Setiap hari petugas sanitasi memeriksa secara berkala untuk memastikan toilet dalam keadaan bersih dan lengkap. Jumlah toilet disesuaikan dengan jumlah karyawan produksi. Sarana toilet karyawan menggunakan sistem air mengalir. Sarana pencuci tangan dilengkapi dengan sabun cuci tangan dan hand dryer yang selalu di monitoring oleh petugas sanitasi. Sarana pencuci tangan karyawan menggunakan sistem air mengalir untuk meminimalisasi kontaminasi silang menggunakan pedal injak. Di dalam bak cuci kaki (footbath) dilakukan penambahan larutan desinfektan (klorin 100-200 ppm) (Estiasih \& Ahmadi, 2016).

e) Bahan Kimia, Pembersih dan Saniter

Gudang penyimpanan bahan kimia non makanan seperti pelumas, sanitizer dan desinfektan ditempatkan di ruang bahan kimia yang terpisah dengan ruang produksi. Semua bahan kimia yang digunakan diberi label sesuai dengan jenisnya. Semua bahan kimia non pangan yang diterima oleh perusahaan harus dilengkapi dengan Material Safety Data Sheet yang telah divalidasi oleh pihak produsen, supplier atau distributor. Pemakaian bahan kimia non pangan dicatat pada log book yang menjelaskan tanggal pemakaian, tujuan penggunaan, sisa pemakaian dan keterangan pengguna bahan.

\section{f) Syarat Pelabelan dan Penyimpanan}

Label harus sesuai dengan isi produk yang ada di dalam kemasan dan dilakukan pemerikasaan terlebih dahulu sebelum dilakukan pelabelan. Label yang digunakan harus memuat informasi yang lengkap seperti jenis produk, tanggal produksi, syarat penyimpanan, perusahaan yang memproduksi, merk dan berat bersih, syarat penyajian dan spesifikasi produk. Pelabelan dilakukan terhadap kemasan primer dan kemasan sekunder. Gudang penyimpanan bahan kimia terdapat di luar area proses produksi, penyimpanan bahan kimia dengan dilakukan dengan pemberian label dan mengisi form pengambilan bahan kimia. Penyimpanan ditata sehingga mempermudah identifikasi produk serta disusun dengan rapi sesuai jenis produk (Effendi, 2015).

\section{g) Pengawasan Kondisi Kesehatan Karyawan}

Karyawan yang menderita sakit pencernaan dan mengalami luka di bagian tangan tidak boleh bekerja di area produksi. Setiap karyawan baru yang bekerja di unit produksi harus melampirkan surat keterangan sehat dari dokter pada saat penerimaan karyawan. Setiap 6 bulan sekali karyawan yang bekerja di unit produksi diperiksa kondisi kesehatannya melalui lembaga medis yang terakreditasi.

h) Pengendalian Pest

Pengendalian pest dilakukan dengan menjaga kebersihan lingkungan unit pengolahan, yaitu dengan membuang sampah ke tempat penampungan sementara sebelum diambil oleh pekerjaan umum dari pihak pemerintah. Penjagaan kebersihan lingkungan perusahaan dilakukan oleh 
petugas kebersihan sedangkan pengendalian hama berupa tikus, serangga, kucing, dan hama lainnya bekerja sama dengan perusahaan lain. Hama yang dikendalikan dalam program ini adalah jenis binatang yang berpeluang menimbulkan kontaminasi silang terhadap proses produksi seperti tikus, serangga dan lain-lain.

\section{Kesimpulan}

Penerapan GMP telah dilaksanakan dengan baik sesuai tahapan produksi terdiri dari penerimaan bahan baku ikan beku, thawing (pelelehan), penyiangan, pengisian ikan ke dalam kaleng, precooking (pemasakan pendahuluan), penirisan, pembuatan dan pengisian media vegetable oil, penutupan kaleng, pencucian kaleng, sterilisasi, pendinginan, pengkodean, inkubasi, pengepakan, penyimpanan dan pengiriman. Penerapan SSOP telah dilaksanakan dengan baik dan cukup efektif untuk mengurangi/menghilangkan kontaminasi terhadap produk akhir dan telah sesuai dengan standard prosedur yang telah ditetapkan oleh perusahaan.

\section{Daftar Pustaka}

Adawyah, R. (2014). Pegolahan dan Pengawetan Ikan. Bumi Aksara.

Arini, \& Sri Subekti. (2019). Proses Pengalengan Ikan Lemuru (Sardinella longiceps) di CV . Pasific Harvest Banyuwangi , Provinsi Jawa Timur . Marine and Coastal Science, 8 (2)(June), 56-65.

Astawan, M. (2019). Penanganan dan Pengolahan Hasil Perikanan. Universitas Terbuka.

Badan Pengawas Obat dan Makanan Republik Indonesia. (2019). Peraturan Badan Pengawas Obat Dan Makanan Nomor 22 Tahun 2019 Tentang Informasi Nilai Gizi Pada Label Pangan Olahan. In Badan Pengawas Obat dan Makanan (Nomor 22 Tahun 2019).

Badan Standardisasi Nasional. (2014). Ikan Beku (SNI 4110:2014). BSN.

Badan Standardisasi Nasional. (2016). Sarden dan makerel dalam kemasan kaleng (SNI 8222 : 2016). BSN.

BRC Global Standards. (2018). Global Standard for Food Safety (Issue 8). BRC Global Standards. https://doi.org/10.1002/9781118373828

Effendi, M. S. (2015). Teknologi Pengolahan dan Pengawetan Pangan (3rd ed.). Alfabeta.

Estiasih, T., \& Ahmadi, K. (2016). Teknologi Pengolahan Pangan (2nd ed.). Bumi Aksara.

Fatkhurrozi Syah, N., \& Pramono, H. (2019). Implementasi Tata Letak Proses Produksi pada Industri Pengalengan Rajungan (Portunus Pelagicus) PT. Sumber Mina Bahari Rembang Application of Production Process Layout At the canning and swimming crab (Portunus pelagicus) in PT. Sumber Mina Bahari Rembang. Journal of Marine and Coastal Science, 8(1), 1-9.

Gusdi, A. T., \& Sipahutar, Y. H. (2021). Pengolahan Fillet Ekor Kuning (Caseo Cunning) Beku di PT Duta Pasific Buana, Bangka Belitung. Prosiding Simposium Nasional VIII Kelautan Dan Perikanan Fakultas IImu Kelautan Dan Perikanan, Universitas Hasanuddin, Makassar, 5 Juni 2021, 37-44.

Hadinata, S. T., \& Adriyanto, H. (2020). Tinjauan Penyimpanan Sistem Fifo Pada Bahan Hewani Yang Berdampak Pada Proses Pengolahan Makanan Di Morrissey Hotel Jakarta. Emerging Markets : Business and Management Studies Journal, 6(2), 103-109. https://doi.org/10.33555/ijembm.v6i2.100

Hafina, A., Sipahutar, Y. H., \& Siregar, A. N. (2021). Penerapan GMP dan SSOP pada Pengolahan Udang Vannamei( Litopenaeus vannamei ) Kupas Mentah Beku Peeled Deveined ( PD ). Jurnal Aurelia, 2(3457), 117-131.

Irianto, H. E., \& Akbarsyah, T. M. I. (2007). Pengalengan Ikan Tuna Komersial. Squalen Bulletin of Marine and Fisheries Postharvest and Biotechnology, 2(2), 43. https://doi.org/10.15578/squalen.v2i2.136

Irianto, H. E., \& Giyatmi, S. (2015). Teknologi Pengolahan Hasil Perikanan. In Universitas Terbuka, Tangerang Selatan (Vol. 2). 
Aurelia Journal, Vol. 3 (1): $11-24$

Jacobus, S. I., \& Sumarauw, J. S. (2018). Analisis Sistem Manajemen Pergudangan Pada CV. Pasific Indah Manado. Jurnal EMBA: Jurnal Riset Ekonomi, Manajemen, Bisnis Dan Akuntansi, 6(4), 22782287. https://doi.org/10.35794/emba.v6i4.20996

Kementrian Kelautan dan Perikanan. (2019). Peraturan Menteri Kelautan dan Perikanan RI tentang Persyaratan dan Tata Cara Penerbitan Sertifikat Kelayakan Pengolahan (Nomor 17/PERMENKP/2019). KKP.

Kementrian Perindustrian. (2020, April 24). Industri Pengalengan Ikan Tumbuh di Tengah Pandemi Covid19. Kementrian Perindustrian.

Kusnandar, P. H. (2010). Teknologi Pengalengan Pangan.

Ma'roef, A. F., Sipahutar, Y. H., \& Hidayah, N. (2021). Penerapan Good Manufacturing Practice (GMP) dan Sanitation Operating Prosedure (SSOP) pada Proses Pengalengan Ikan Lemuru (Sardenella Longiceps) dengan Media Saos Tomat. Prosiding Simposium Nasional VIII Kelautan Dan Perikanan Fakultas IImu Kelautan Dan Perikanan, Universitas Hasanuddin, Makassar, 5 Juni 2021, 143-154.

Masengi, S., \& Sipahutar, Y. H. (2016). Produktivitas tenaga kerja pada pengolahan Tuna Loin Mentah Beku PT lautan Niaga Jaya, Muara Baru, Jakarta Utara. Jurnal STP(Teknologi Dan Penelitian Terapan), 2, 28-39.

Masengi, S., Sipahutar, Y. H., \& Rahardian, T. (2016). Penerapan Sistem Ketertelusuran (Traceability) pada Pengolahan Udang Vannamei (Litopenaus vannamei) Kupas mentah beku (Peeled and Defeined) di PT dua Putra Utama Makmur, Pati Jawa Tengah. Jurnal STP (Teknologi Dan Penelitian Terapan), 1, 201-210.

Maurina, F., \& Sipahutar, Y. H. (2021). Pengolahan Rajungan (Portunus pelagicus) Pasteurisasi dalam Cup di PT Muria Bahari Indonesia, Kudus, Jawa Tengah. Prosiding Simposium Nasional VIII Kelautan Dan Perikanan Fakultas IImu Kelautan Dan Perikanan, Universitas Hasanuddin, Makassar, 5 Juni 2021, 133-142.

Mayangsari, T. P., \& Sipahutar, Y. H. (2021). Pengolahan Fillet lkan Kerapu (Epinephelus sp) Beku di PT Bintas Intas Gemilang, Binta, Kepulauan Riau. Prosiding Simposium Nasional VIII Kelautan Dan Perikanan Fakultas IImu Kelautan Dan Perikanan, Universitas Hasanuddin, Makassar, 5 Juni 2021, 93-102.

Pusat Sertifikasi Mutu dan Keamanan Hasil Perikanan. (2014). Petunjuk Teknis Inspeksi Cara Penanganan Ikan yang Baik (CPIB) Berdasarkan Konsepsi HACCP pada Unit Pengumpul/Supplier. Badan Karantina Ikan, Pengendalian Mutu dan Keamanan Hasil Perikanan.

Putrisila, A., \& Sipahutar, Y. H. (2021). Kelayakan Dasar Pengolahan Udang Vannamei (Litopenaeus vannamei) Nobashi Ebi. Jurnal Airaha, 10(1), 10-23.

Sahubawa, L., \& Ustadi. (2019). Teknologi Pengawetan dan Pengolahan Hasil Perikanan (U. Santoso (ed.); 3rd ed.). Gajah Mada University Press.

Sipahutar, Y. H., Djajuli, N., \& Hasibuan, L. E. A. (2010). Penerapan HACCP (Hazard Analysis Critical Control Point) Pada Proses Pengalengan Ikan Lemuru (Sardinella lemuru) di PT. X Banyuwangi. Prosiding Seminar Nasional Perikanan Indonesia, Sekolah Tinggi Perikanan, Jakarta, 02-03 Desember 2010, 486-499.

Sofiah, S. L., \& Ramli. (2012). Penerapan Good Manufacturing Practices (GMP) Dan Sanitation Standard Operating Prosedure (SSOP) Pada Tahapan Proses Produksi Sarden. Samakia, 3(2), 28-37.

Supenah, P. (2019). Identifikasi Bakteri Clostridium Botulinum pada Sarden Kemasan Kaleng berbagai merk yang di jual di swalayan X. Syntax Litertatur, Jurnal ILmiah Indonesia, 4(4), 146-150.

Suryanto, M. R., \& Sipahutar, Y. H. (2020). Penerapan GMP dan SSOP pada Pengolahan Udang Putih (Litopenaeus vannamei) Peeled Deveined Tail On (PDTO) Masak Beku di Unit Pengolahan Ikan Banyuwangi. In Prosiding Seminar Kelautan Dan Perikanan Ke VII , Fakultas Kelautan Dan Perikanan, Universitas Nusa Cendana, 18-20 November 2020, 204-222. 
Sutriyati, Badraningsih, \& Prihastuti, E. (2004). Teknik Pengolahan Ikan Laut. Inotek, 8(2), 175-182.

Syah, D. (2012). Pengantar Teknologi Pangan.

Syarief, R., \& Syukri, A. (2016). Pengemasan Pangan (Eds 2/Modu). Universitas Terbuka.

Thaheer, H. (2005). Sistem Manajemen HACCP (Hazard Analysis Critical Control). Bumi Aksara.

Vatria, B. (2006). Pengalengan Ikan Lemuru (Sardinella Lemuru Fish Canning). Belian, 5(3), 174-181.

Winarno, F. G. (2011). Good Manufacturing Practices (GMP). M-Brio Press.

Winarno, F. G., \& Surono. (2004). GMP Cara Pengolahan Pangan Yang Baik. M-Brio Press.

Zahirah, R. M. (2020). Manajemen Bahan Baku Ikan Lemuru (Sardinella Longceps) di CV Pasific Harvest, Banyuwangi, Jawa Timur. Repository Universitas Airlangga.

Zhafirah, F., \& Sipahutar, Y. H. (2021). Proses Pengolahan Ikan Tongkol Abu-abu (Thunnus tonggol) dalam Kaleng dengan Media Air Garam di PT. Jui Fa Interbational Food, Cilcap-Jawa Tengah. In Prosiding Simposium Nasional VIII Kelautan Dan Perikanan Fakultas IImu Kelautan Dan Perikanan, Universitas Hasanuddin, Makassar, 5 Juni 2021, 57-68. journal.unhas.ac.id/index.php/proceedingsimnaskp/issue/view/1040 